\title{
Relationship Between Metacognitive Skills and Information Processing Skills Among Al-Quds University Students
}

\author{
Omar Rimawi, Associate Professor \\ Department of Psychology, Al-Quds University, Palestine \\ Amira Rimawi, Assistant Professor \\ Department of Special Education, Al-Quds University, Palestine
}

Doi:10.19044/esj.2020.v16n19p262 URL:http://dx.doi.org/10.19044/esj.2020.v16n19p262

\begin{abstract}
Metacognitive skills and information processing are key concepts in the field of education, they are crucial in the learning process. The present study aimed to identify the relationship between metacognitive skills and information processing skills among the students of Al-Quds University. The study instruments were applied on a sample of 393 male and female students. The results showed that there was a positive correlation between metacognitive skills and information processing among Al-Quds University students. The findings revealed statistically significant differences in the level of metacognitive skills, attributed to gender in favor of female students. However, there were no statistically significant differences due to faculty or academic level. The findings also showed that there were no statistically significant differences in the level of information processing skills attributable to gender and academic level. However, there were statistically significant differences in the level of information processing due to the faculty variable in favor of the Faculty of Science.
\end{abstract}

Keywords: Metacognition; Information Processing; Al-Quds University

\section{Introduction}

Modern times are characterized by many successive changes and rapid developments in various aspects of life. Such changes and developments affect the personality of individuals, in general, and students, in particular. This fact makes it extremely necessary for us to help our students build their balanced personality in its different aspects and in different academic stages, as well as invest their mental potentials in a way that corresponds to these changes and developments and keeps pace with them (Abdulhadi, 2017). 
Metacognitive skills are considered one of the modern topics that scientific research has started to address (Ramadan, 2004). There has been a growing interest and a large increase in the studies conducted in the field of Cognitive Psychology as they reflect the individual's way to solve problems, decision-making, information processing, evaluation, and utilization (Ramadan, 2004).

Psychologists are interested in metacognitive skills increased in 1980s, since then, this topic has received a lot of attention as a new method of teaching thinking (Romainville, 2007: 17). With the help of these skills, it is possible to explore individual differences in cognitive areas, including perception, memory, thinking, and the ability to process information (AlAhmad, 2010). The ultimate goal of developing metacognitive skills is to teach students how to autonomously think and evaluate themselves (Nofal \& Saifan, 2011: 270).

The importance of metacognitive skills lies in increasing the learner's (student's) ability to plan, monitor, assess their skills, and render their learning processes from quantitative to qualitative learning (Salami, 2012, p. 17).

Al-Sherbiny and El-Tantawi (2006) discussed some didactic aspects of metacognitive thinking such as developing the learner's ability to choose, renew, and innovate, which would enable them to generate creative ideas, increase their awareness of information processing methods, and improve their comprehension.

Rickey and Stacy (2000) indicated that students' awareness of Metacognition increases their academic achievement and helps them to use knowledge in different situations. Similarly, Metacognition allows students to understand what they study and improves their capabilities of comprehension and self-organization during learning (Kornell \& Metcalfe, 2006).

Metacognitive skills have an effect on human performance in coping with various educational situations and on their academic achievements (Jain, Tiwari, \& Awasthi, 2017). A number of researchers believe that learners' poor ability to remember their previous knowledge can be due to several factors, including their failure to encode information or their inaccuracy in storing it during the operation of information processing (Al-Atoum, 2004, p. 137), Cook and Mayer (1983) concluded that learners' weakness in academic subjects in general is due to their shallow and superficial methods of information processing. Developing a strategy for information processing has become an essential educational requirement (Al-Khazraji, 2011, p. 5).

\section{Related Literature}

Kashash and Ash-Shariefy (2019) showed that there were statistically significant differences in the effect of information processing strategy on increasing student achievement Braik (2019) demonstrated that there were no 
statistically significant differences between the means of metacognitive skills and academic adjustment scores due to the Faculty of Science or the Faculty of humanities. While Qaydoom indicated, in his study (2018), that there was a statistically significant correlation in favor of the students who most commonly use metacognitive learning strategies in processing information.

The findings of Bounaqah's study (2017) revealed that there was a positive correlation between metacognitive thinking and self-organized learning strategies. However, the study found no statistically significant differences in the correlation due to the gender or academic major (Scientific or Literary). A study conducted by Abdussahib, Hasan and Yaber (2017) indicated that there were no statistically significant differences in cognitive failures among university students. The study also showed that university students tended to use strategic style, and they had the ability to solve problems. The study stressed that cognitive failures played a role in deep and shallow treatment methods which are used in processing information, AlJuhani (2016) concluded that students' level in metacognitive skills was less than average in information processing.

Sawhney and Bansal (2015) revealed significant differences in academic achievement among students with low metacognitive awareness and those with high metacognitive awareness fin favor of the latter group.

A study conducted by Al-Jarrah and Obeidat (2011) revealed that there were statistically significant differences in the level of metacognitive thinking and information processing in favor of females, on the other hand, it found no statistically significant differences due to academic specialization or academic year. Al-khazraji (2011) concluded that the educational program had a positive impact on student achievement and on increasing their preferences for the information supplementary pattern, application pattern and principles pattern, as well as on their lower preferences for the recalling pattern compared to the control group which was taught traditionally. Al-Rofo' (2011) revealed differences in favor of females and scientific major in information processing.

\section{Problem of the study:}

The need for knowledge, improving it and raising its level one of the basic needs of university students, this highlights the need to use many effective methods, strategies, and skills to help them coordinate the thinking process, as they can direct their energy and efforts to achieve and employ these goals, as well as improving their understanding of the educational task or the strategies they use in learning process. This study aims to expose the relationship between the level of students' use of metacognitive skills and information processing for Al-Quds University students? 


\section{Purpose and Scope}

The study addressed the relationship between metacognitive skills and information processing among Al-Quds University students. Metacognitive skills and information processing are key concepts in the field of education and they are essential in learning process. The significance of the study stems from the importance of its topic and the targeted sector in the Palestinian society. Metacognitive skills play a vital role in academic achievement and influence Students' abilities to plan, monitor, and assess their learning skills and processes.

\section{Hypotheses}

The study proposed the following hypotheses:

- There is no statistical significant correlation between metacognitive skills and information processing among Al-Quds University students.

- There are no statistical significant differences at 0.05 level of significance in metacognitive skills and information processing among Al-Quds University students according to gender, faculty and academic level.

\section{Methodology Approach}

The study adopted the Descriptive Correlational Method to achieve its objectives. This method can be defined as an approach that studies a current phenomenon, event or issue from which the necessary information to answer research questions or hypotheses can be (Allam, (2012) Through this type of research methods, it is possible to know whether there is a relationship between two or more variables, and then identify the degree of that relationship.

\section{Population and Sampling}

The study population included all first-term undergraduate students in Al-Quds University for the academic year 2019/2020. They were 9300 male and female students, according to the Department of Admission and Registration of Al-Quds University. The study sample consisted of 393 male and female regular students with various academic levels and majors at AlQuds University. Male students represented (38.7\%) while female students were $(61.3 \%)$, who were selected in a random and stratified method to represent the study sample. 400 questionnaires were distributed to Al- Quds University students; seven respondents' questionnaires were excluded as they were not accurate, and 393 questionnaires were analyzable. Table 1 shows the distribution of the respondents according to study variables. 
Table 1: Distribution of respondents according to study variables

\begin{tabular}{cccc}
\hline Variable & Level & $\mathrm{N}$ & Percent \% \\
\hline Gender & Male & 152 & 38.7 \\
& Female & 241 & 61.3 \\
Faculty & Science & 186 & 47.3 \\
& Arts & 207 & 52.7 \\
& First & 68 & 17.3 \\
& Second & 65 & 16.5 \\
& Third & 93 & 23.7 \\
& Fourth + & 167 & 42.5 \\
\hline
\end{tabular}

\section{Instrumentation}

Having reviewed the instruments used in a number of previous studies and related literature, the study adopted Schraw and Dennison's Arabic version of metacognitive skills measurement (Schraw \& Dennison: 1994). It also was applied in the study of Al-Jarrah and Obeidat (2011). This measurement consisted of 33 statements (See a sample of the questionnaire annexed to Appendix A). In addition, the study used the measurement of information processing which is originally developed by Aljaf and Jani (2011), it consisted of 25 statements (See a sample of the measurement annexed to Appendix A). A five-point Likert scale was also used to measure the responses and correction method, as follows: very extremely (5 degrees), extremely (4 degrees), moderately (3 degrees), slightly ( 2 degrees), very slightly (1 degree).

The instruments were validated and examined at two different stages. The first stage conducted by a number of experts who provided feedback on the instruments. While the second stage were a pilot study $(n=30)$ to check the statistical evidence of instruments validity by means of the Exploratory Factor Analysis (EFA). The loading factor for all elements exceeded 0.75 (from 0.76 to 0.89 ), which implied that these elements were able to measure any component of metacognitive and information processing skills.

Cronbach's Alpha coefficient was used to test the reliability and consistency of the study findings. The coefficients for metacognitive skills and information processing skills were respectively $(0.90,0.76)$, which implied excellent reliability and consistency.

\section{Data Analysis}

Statistical Package for Social Sciences (SPSS) was used to analyze the collected data. Means and standard deviations were also calculated. T-test, One-Way ANOVA, Cronbach's Alpha, and Pearson Correlation Coefficient were used. 


\section{Results}

The results were as follows:

Table 2. Pearson correlation between metacognitive skills and information processing for Al-Quds University students

\begin{tabular}{|c|c|c|c|}
\hline Variable & & r-value & Sig. \\
\hline Metacognitive skills & $\begin{array}{l}\text { Information } \\
\text { processing }\end{array}$ & $.511^{* *}$ & 0.00 \\
\hline
\end{tabular}

Table (2) shows that the value of the Pearson Correlation Coefficient for the overall score is $(0.51)$ at 0.00 significance level, which means that there is a statistically significant positive relationship at $(\mathrm{p}<0.05)$ between metacognitive skills and information processing.

Table 3. T-test for the differences in metacognitive skills scores among Al-Quds University students based on gender variable

\begin{tabular}{ccccccc}
\hline Field & Gender & $\mathrm{N}$ & Mean & SD & T-value & Sig. \\
\hline Knowledge organization & Male & 152 & 3.68 & .46 & -6.215 & .004 \\
& Female & 241 & 3.99 & .53 & & \\
Knowledge & Male & 152 & 3.73 & .43 & -5.459 & .000 \\
& Female & 241 & 4.01 & .56 & & \\
Cognitive processing & Male & 152 & 3.70 & .41 & -5.808 & .003 \\
& Female & 241 & 3.97 & .50 & & \\
Metacognitive & Male & 152 & 3.70 & .38 & -6.483 & .000 \\
& Female & 241 & 3.99 & .49 & & \\
\hline
\end{tabular}

Table 3 shows that there are statistically significant differences in the level of metacognitive skills among Al-Quds University students due to gender in favor of female students $(\overline{\mathrm{x}}=3.99 ; \mathrm{SD}=0.49)$ compared to male students $(\overline{\mathrm{x}}=$ $3.70 ; \mathrm{SD}=0.38)$. t- test value is $(-6.48, \mathrm{P}=0.00)$.

Table 4. T-test scores for the differences in metacognitive skills scores among Al-Quds University students according to the faculty variable.

\begin{tabular}{|c|c|c|c|c|c|c|}
\hline Field & Faculty & $\mathrm{N}$ & Mean & SD & T-value & Sig. \\
\hline Knowledge & Science & 186 & 3.88 & .52 & \multirow{2}{*}{219} & \multirow{2}{*}{.827} \\
\hline organization & Arts & 207 & 3.86 & .52 & & \\
\hline Knowledge of & Science & 186 & 3.92 & .53 & \multirow{2}{*}{.806} & \multirow{3}{*}{421} \\
\hline knowledge & Arts & 207 & 3.88 & .53 & & \\
\hline Cognitive & Science & 186 & 3.88 & .49 & \multirow[b]{2}{*}{679} & \\
\hline processing & Arts & 207 & 3.85 & .48 & & .497 \\
\hline Metacognitive & $\begin{array}{c}\text { Science } \\
\text { Arts }\end{array}$ & $\begin{array}{l}186 \\
207\end{array}$ & $\begin{array}{l}3.90 \\
3.87\end{array}$ & $\begin{array}{l}.47 \\
.47\end{array}$ & .605 & .546 \\
\hline
\end{tabular}


Table 5. One way analysis for the differences in the level of metacognitive skills among AlQuds University students due to the academic level variable.

\begin{tabular}{|c|c|c|c|c|c|c|}
\hline Field & Academic level & $\mathrm{N}$ & Mean & SD & F-value & Sig. \\
\hline \multirow[t]{4}{*}{$\begin{array}{c}\text { Knowledge } \\
\text { organization }\end{array}$} & First & 68 & 3.92 & .55 & .860 & .462 \\
\hline & Second & 65 & 3.79 & .52 & & \\
\hline & Third & 93 & 3.91 & .45 & & \\
\hline & Fourth + & 167 & 3.86 & .55 & & \\
\hline \multirow[t]{4}{*}{$\begin{array}{l}\text { Knowledge of } \\
\text { knowledge }\end{array}$} & First & 68 & 3.97 & .56 & 1.224 & .301 \\
\hline & Second & 65 & 3.81 & .55 & & \\
\hline & Third & 93 & 3.94 & .48 & & \\
\hline & Fourth + & 167 & 3.88 & .53 & & \\
\hline \multirow[t]{4}{*}{$\begin{array}{l}\text { Cognitive } \\
\text { processing }\end{array}$} & First & 68 & 3.98 & .49 & 1.583 & .193 \\
\hline & Second & 65 & 3.83 & .48 & & \\
\hline & Third & 93 & 3.86 & .47 & & \\
\hline & Fourth + & 167 & 3.83 & .49 & & \\
\hline \multirow{4}{*}{ Metacognitive } & First & 68 & 3.95 & .50 & 1.197 & .311 \\
\hline & Second & 65 & 3.81 & .48 & & \\
\hline & Third & 93 & 3.91 & .42 & & \\
\hline & Fourth + & 167 & 3.86 & .49 & & \\
\hline
\end{tabular}

However, as shown in tables 4 and 5 , there are no statistically significant differences at $(\alpha \geq 0.05)$ in the level of metacognitive skills among Al-Quds University students due to the academic level and faculty variables.

Table 6. T-test scores for the differences in the level of information processing for Al-Quds University students based on gender variable.

\begin{tabular}{|c|c|c|c|c|c|c|}
\hline Field & Gender & $\mathrm{N}$ & Mean & $\mathrm{SD}$ & T-value & Sig. \\
\hline \multirow{2}{*}{$\begin{array}{l}\text { In-depth } \\
\text { treatment }\end{array}$} & Male & 152 & 3.50 & .55 & \multirow[b]{2}{*}{1.62} & \multirow[b]{2}{*}{.100} \\
\hline & Female & 241 & 3.41 & .49 & & \\
\hline \multirow{2}{*}{$\begin{array}{l}\text { Extended } \\
\text { processing }\end{array}$} & Male & 152 & 3.23 & .46 & \multirow[b]{2}{*}{.930} & \multirow[b]{2}{*}{.340} \\
\hline & Female & 241 & 3.19 & .41 & & \\
\hline \multirow{2}{*}{$\begin{array}{l}\text { Total degree } \\
\text { information } \\
\text { processing }\end{array}$} & \multirow{2}{*}{$\begin{array}{l}\text { Male } \\
\text { Female }\end{array}$} & 152 & 3.38 & .46 & \multirow[b]{2}{*}{1.57} & \multirow[b]{2}{*}{.130} \\
\hline & & 241 & 3.31 & .39 & & \\
\hline
\end{tabular}


Table 7. T-test scores for the differences between the participants in the level of information processing for Al-Quds University students based on the faculty variable.

\begin{tabular}{ccccccc}
\hline Field & Faculty & $\mathrm{N}$ & Mean & SD & T-value & Sig. \\
\hline In-depth treatment & Science & 186 & 3.49 & .55 & \multirow{2}{*}{1.65} & \multirow{2}{*}{.090} \\
& Arts & 207 & 3.40 & .47 & & \\
Extended processing & Science & 186 & 3.26 & .45 & \multirow{2}{*}{2.13} & .030 \\
& Arts & 207 & 3.16 & .42 & & \\
Total degree for & Science & 186 & 3.39 & .45 & \multirow{2}{*}{2.09} & .030 \\
Information processing & Arts & 207 & 3.30 & .39 & & \\
\hline
\end{tabular}

Similarly, as shown in table 6 and 7 , there are no statistically significant differences at $(\alpha \geq 0.05)$ in the level of information processing among Al-Quds University students based on variables of academic level and gender.

Table 8. One way analysis of variance for the differences in the level of information

processing for Al-Quds University students according to the academic level variable.

\begin{tabular}{ccccccc}
\hline Field & Academic level & N & Mean & SD & F-value & Sig. \\
\hline In-depth treatment & First & 68 & 3.50 & .59 & & \\
& Second & 65 & 3.43 & .55 & .306 & .821 \\
& Third & 93 & 3.45 & .46 & & \\
& Fourth + & 167 & 3.43 & .50 & & \\
Extended processing & First & 68 & 3.19 & .52 & & \\
& Second & 65 & 3.25 & .48 & .507 & .677 \\
& Third & 93 & 3.23 & .39 & & \\
Total degree for & Fourth + & 167 & 3.18 & .40 & & \\
information processing & First & 68 & 3.36 & .49 & & \\
& Second & 65 & 3.35 & .47 & .250 & .861 \\
& Third & 93 & 3.35 & .37 & & \\
& Fourth + & 167 & 3.32 & .40 & & \\
\hline
\end{tabular}

Table 8 shows that there are statistically significant differences in the level of information processing among Al-Quds University students based on the faculties in favor of science faculty $(\overline{\mathrm{x}}=3.39$, SD 0.45) compared the Humanities $(\overline{\mathrm{x}}=3.30 \mathrm{SD} 0.39)$. $\mathrm{t}$-test value is $(2.09, \mathrm{P}=0.03)$.

\section{Discussion}

The results of this study show that there is a statistically significant positive correlation between metacognitive skills and information processing this was consistent with result of Qaydoom (2018), Bounaqah (2017), Sawhney and Bansal (2015) and Al-Khazraji (2011) while it was inconsistent with Abdussahib, Hasan and Yaber (2017) and Al-Juhani (2016). This relationship confirms the influence of metacognitive skills and information processing, and vice versa. This finding underscores the importance of teaching and learning these skills because of their contributions in students' 
academic and social life, this result were supported by the study of Al-Jarrah and Obeidat (2011).

The results of the study also revealed that there are statistically significant differences in the level of metacognitive skills due to gender and fields in favor of female students. This result is consistent with a study by AlJarrah and Obeidat (2011), but it inconsistent with Bounaqah (2017). This result also indicates that female students use metacognitive skills more than male students, as they are better than male students in terms of academic achievement and the desire to excel and obtain high academic grades.

The results, however, show no statistically significant differences attributable to faculty, specialization or academic level. This result is consistent with Braik (2019), Bounaqah (2017), and Al-Jarrah \& Obeidat (2011). This can be attributed to a lack of student training on metacognitive skills throughout the university years.

The analysis also revealed that there are no statistically significant differences in the level of information processing due to gender and academic level, this result was consistent with Al-Jarrah \& Obeidat (2011) for the academic level but disagreed with it for gender, while it was inconsistent with Al-Rofo' (2008) for the gender. This may be attributed to the traditional method of teaching that students obtain at the undergraduate level.

However, there are differences in the level of information processing due to the faculty and the fields in favor of the Faculty of Science this agreed with Al-Rofo' (2008) but disagreed with Al-Jarrah \& Obeidat (2011). This may be attributed to the subjects and nature of scientific disciplines.

\section{Conclusions and Recommendations}

Based on the above results, the following can be concluded:

- Attention must be paid to the complementary interactive relationship between metacognitive skills and information processing in the university students' teaching and learning processes which require the creation of productive learning goals, not retrospective learning.

- Females are more accurate, well organized, and they can monitor and evaluate learning more than males as they have a desire to assert themselves, succeed, and obtain a position in society.

- Faculties of Science faculties influence students' thoughts and the manner in which they process information more than Faculties of Humanities do.

- Inviting those who are responsible for educational process in universities to adopt teaching methods and approaches that take into account students' educational traits so that they are armed with metacognitive skills and the best ways to process information. 
- Inviting researchers to perform studies that demonstrate how to educate Faculties of Humanities' students about how to manage knowledge that can be used in daily life.

Therefore, further research should be conducted on the topic under discussion. based on the above results and discussion, the study recommends the following actions:

- Paying a special attention to metacognitive and information processing skills and incorporate them in the curriculum, in other words they should be included in the curricula and involved in the educational strategies designed specifically to develop and present metacognitive skills.

- Giving priority to the development of metacognitive and information processing skills as they require direct guidance at the beginning to enable the students to perform these skills.

\section{References:}

1. Abdulhadi, M. (2017). The impact of metacognitive strategies on developing critical thinking among the female students of the Department of Kindergartens. University of Thi-Qar Journal, 12 (1), 105-133. (Arabic version)

2. Abdussahib, M. Hassan, F. \& Yaber, Kh. (2017). Cognitive failures and their relationship to methods of information processing and problem solving among university students. Journal of Educational and Psychological Research, 14 (55), 125-150. (Arabic version)

3. Al-Ahmad, A. (2010). Cognitive styles and their relationship to some personal variables. Student Teacher Journal, (2), 5-14, UNRWA Institute of Education-UNESCO. Amman: Jordan. (Arabic version)

4. Al-Atoum, A. (2004). Cognitive psychology: Theory and practice. Dar Al-Masirah for Publishing, Distribution \& Printing. Amman: Jordan. (Arabic version)

5. Aljaf, R. \& Jani, N. (2011). Methods of information processing and its relationship to exam anxiety among female student teachers in teacher education institutes. Mustansiriyah Journal of Arts, 55 (1), 1-49. (Arabic version)

6. Al-Jarrah, A. \& Obeidat, A. (2011). Metacognitive thinking level amongst a sample of Yarmouk University students in the light of some variables. Jordan Journal of Educational Sciences, 7 (2), 145-162. (Arabic version)

7. Al-Juhani, A. (2016). The relation of academic adaptation with stumbling through metacognition and the personality characteristics of 
Saudi Students on Scholarships in New Zealand. Journal of Arab Studies in Education and Psychology, (73), 255-296. (Arabic version)

8. Al-Khazraji, A. (2011). Building an educational program according to information processing strategies in cognition achievement and preference among female students of the Department of Life Sciences and the development of their critical thinking (Unpublished doctoral dissertation). Ibn Al-Haytham College, University of Baghdad: Iraq. (Arabic version)

9. Allam, S. (2012), Educational Research, Competencies for Analysis and Application, Amman, Jordan. Dar Alfaker, Publishers and distributers.

10. Al-Rofo, M. (2008). Information Processing Methods for High School Students in Jordan and their Relationship to Gender and Major. Damascus University Journal for Educational Sciences. M 24, p. $2,2$.

11. Al-Sherbiny, F. \& El-Tantawi, E. (2006). Metacognitive strategies between theory and practice. The Modern Bookshop for Publishing and Distribution. Al-Mansoura: Egypt. (Arabic version)

12. Bounaqah, N. (2017). Thinking beyond knowledge and its relationship to self-organized learning strategies for third-year pupils in secondary education: Tlemcen city as a model. Journal of Psychological and Educational Sciences, 4 (2), 31-56. (Arabic version)

13. Braik, E. (2019). Metacognitive skills as predictors of academic adjustment among first year students at King Saud University. Jordan Journal of Educational Sciences, 15 (1), 65-77. (Arabic version)

14. Cook, L., \& Mayer, R. (1983). Reading strategies training for meaningful learning from prose. In: Cognitive strategy research (pp. 87-131). Springer, New York, NY.

15. Jain, D., Tiwari, G. K., \& Awasthi, I. D. (2017). Impact of Metacognitive Awareness on Academic Adjustment and Academic Outcome of the Students. International Journal of Indian Psychology, 5 (1), 123-138.

16. Kashash, A \& Ash-Shariefy, M. (2019). The impact of strategic information processing and scientific stations on the achievement of students of Ibn Rushd College of Education for Humanities. The Arab Journal of Educational and Psychological Sciences, (7), 121-136. (Arabic version)

17. Kornell, N., \& Metcalfe, J. (2006). Study efficacy and the region of proximal learning Framework. Journal of Experimental Psychology, $32(3), 609-622$.

18. Nofal, M. \& Saifan, M. (2011). Incorporating thinking skills into academic content. Dar Al-Masirah for Publishing, Distribution \& Printing. Amman: Jordan. (Arabic version) 
19. Qaydoom, A. (2018). The Impact of Metacognitive Learning Strategies on Student Achievement. El-Bahith Review in Social and Human Sciences, 10 (2), 2170-1121. (Arabic version)

20. Ramadan, A. (2004). The impact of cognitive style interaction and treatments on the achievement of high school students in natural history (Unpublished Master Thesis). Cairo University: Egypt. (Arabic version)

21. Rickey, D. \& Stacy, A. (2000). The Role of metacognition in learning chemistry. Journal of Chemical Education, 77(7) ,915-920.

22. Romainville, M. (2007). Conscience, métacognition, apprentissage: Le cas des competences méthodologiques. Dans F. Pons, \& P. A. Doudin (eds.), La conscience: perspectives pédagogiques et psychologiques. Québec: Presses de l'université du Québec,108-130.

23. Salami, A. (2012). Metacognition. Al-Amir Typing and Photocopying Office. Bab Al-Muadham. Baghdad: Iraq. (Arabic version)

24. Sawhney, N., \& Bansal, S. (2015). Metacognitive awareness of undergraduate students in relation to their academic achievement. The International Journal of Indian Psychology, 3(1), 107-114.

25. Schraw, G., \& Dennison, R. S. (1994). Assessing metacognitive awareness. Contemporary educational psychology, 19(4), 460-475. 